\title{
PENGOLAHAN LIMBAH KANTONG PLASTIK JENIS KRESEK MENJADI BAHAN BAKAR MENGGUNAKAN PROSES PIROLISIS
}

\author{
Nasrun, Eddy Kurniawan, Inggit Sari \\ Jurusan Teknik Kimia, Fakultas Teknik, Universitas Malilkussaleh \\ Kampus Bukit Indah, Muara Satu, Lhokseumawe, 24352 \\ E-mail : ediekur@gmail.com
}

\begin{abstract}
Abstrak - Pirolisis adalah dekomposisi kimia bahan organik melalui proses pemanasan tanpa atau sedikit oksigen atau reagen kimia lainya dimana material mentah akan mengalami pemecahan stuktur kimia menjadi fase gas. Setelah minyak didistilasi analisa meliputi nilai kalor pembakaran, titik nyala (flash point), kadar abu, kadar air dan analisa komposisi. Nilai kalor pembakaran didapat sebesar $10.541,75 \mathrm{Kcal} / \mathrm{Kg}$. Titik nyala (flash point) tetinggi pada suhu $260^{\circ} \mathrm{C}$ dimenit ke 15 diperoleh sebesar $63,9^{\circ} \mathrm{C}$ pada titik nyala terendah didapat pada suhu $300^{\circ} \mathrm{C}$ dimenit ke 60 diperoleh sebesar $57,5^{\circ} \mathrm{C}$. Kadar abu tertinggi diperoleh pada suhu $300^{\circ} \mathrm{C}$ dimenit ke 60 yaitu $0,26 \%$ dan kadar abu paling sedikit diperoleh pada suhu $2^{260} \mathrm{C}$ dimenit ke 15 yaitu $0,01 \%$. Kadar air terbaik diperoleh pada suhu $300^{\circ} \mathrm{C}$ dimenit ke 60 yaitu $0,01 \%$. Hasil pengujian analisa komposisi menunjukkan persentase terbanyak adalah $\mathrm{C}_{12} \mathrm{H}_{24}$ yaitu sebesar 41,9\%. Dari semua variable yang dipelajari suhu memberikan pangaruh yang paling nyata. Konstanta kecepatan reaksi dipengaruhi oleh suhu sesuai dengan persamaan Arrhenius, dengan nilai aktivasi energi $10.106,77 \mathrm{kj} / \mathrm{mol}$.
\end{abstract}

\section{Keywords — Pirolisis, nilai kalor, titik nyala, kadar abu, kadar} air, analisa komposisi, dan energi aktivasi.

\section{PENDAHULUAN}

Tidak dipungkiri memang kantong plastik jenis kresek telah menjadi bagian hidup manusia dan sulit untuk dipisahkan. Diperkirakan setiap orang menghabiskan 170 kantong plastik setiap tahunnya dan sekitar 500 miliar hingga satu triliun kantong plastik digunakan di seluruh dunia. Serta lebih dari 17 miliar kantong plastik dibagikan secara gratis oleh supermarket di seluruh dunia untuk setiap tahunnya. Bahkan, jika dibentangkan semua kantong plastik yang ada di bumi ini bisa membungkus seluruh permukaan bumi hingga 10 kali lipat. Plastik merupakan material yang sangat akrab dalam kehidupan manusia dan sudah dianggap sebagai bahan pokok kebutuhan rumah tangga ataupun domestik sehingga keberadaan sampah plastik semakin meningkat. Pengolahan sampah plastik menjadi bahan bakar minyak merupakan salah satu pengembangan dari ilmu pengetahuan yang memberikan manfaat positif untuk mengatasi masalah lingkungan, meningkatkan taraf hidup orang banyak, juga menjadi tawaran solusi mencari bahan bakar alternatif. Konversi yang dihasilkan dari proses ini mencapai $60 \%$ bahkan lebih, tergantung dari bahan plastik yang digunakan dan dengan penambahan zat kimia lain (Hakim, 2012). Plastik juga merupakan bahan anorganik buatan yang tersusun dari bahan-bahan kimia yang cukup berbahaya bagi lingkungan. Sampah plastik sangatlah sulit untuk diuraikan secara alami, untuk menguraikan sampah plastik membutuhkan kurang lebih 80 tahun agar dapat terdegradasi secara sempurna.

Oleh karena itu penggunaan bahan plastik dapat dikatakan tidak bersahabat ataupun konservatif bagi lingkungan apabila digunakan tanpa menggunakan batasan tertentu, sedangkan di dalam kehidupan sehari-hari, khususnya kita yang berada di Indonesia, penggunaan bahan kantong plastik jenis kresek ditemukan pada seluruh aktivitas hidup kita (Syafitri, 2001). Berbeda halnya dengan limbah organik, keberadaan sampah kantong plastik jenis kresek dalam tanah tidak dapat diuraikan secara alami sehingga menimbulkan ancaman yang serius terhadap lingkungan. Saat ini jumlah sampah yang terdata tiap harinya yang masuk di Kota Lhokseumawe sekitar 243 $\mathrm{m}^{3} /$ hari yang terbuang sia-sia (Badan Lingkungan Hidup dan Kebersihan Kota Lhokseumawe, 2013).

Pada penelitian ini akan mempelajari pengaruh suhu dan waktu pada proses pirolisis dengan menentukan kondisi optimum dalam proses pirolisis limbah kantong plastik jenis kresek.

\section{Landasan Teori}

\section{Bahan Bakar Minyak}

Bahan bakar juga merupakan bahan yang dapat digunakan untuk menghasilkan energi untuk menghasilkan kerja mekanik secara terkendali. Dengan kata lainadalah zat yang menghasilkan energi, terutama panas yang dapat digunakan. Ditinjau dari sudut teknis dan ekonomis, bahan bakar diartikan sebagai bahan yang apabila dibakar dapat meneruskan proses pembakaran tersebut dengan sendirinya, disertai dengan pengeluaran kalor (Puspita, 2013) 
Adapun jenis-jenis dari bahan bakar minyak diantaranya adalah sebagai berikut:

\section{a. Bensin}

Bensin adalah hidrokarbon berantai pendek antara C4C10 yang biasa digunakan untuk bahan bakar kendaraan bermotor yang berbentuk cairan bening, agak kekuningkuningan, dan berasal dari pengolahan minyak bumi yang sebagian besar digunakan sebagai bahan bakar di mesin pembakaran dalam. Bensin juga dapat digunakan sebagai pelarut, terutama karena kemampuannya yang dapat melarutkan cat. Sebagian besar bensin tersusun dari hidrokarbon alifatik yang diperkaya dengan iso-oktana atau benzena untuk menaikkan nilai oktan.

\section{b. Solar}

Solar adalah fraksi dari pemanasan minyak bumi antara $250-340^{\circ} \mathrm{C}$ yang mempunyai panjang hidrokarbon antara $\mathrm{C}_{16}-\mathrm{C}_{20}$. Solar banyak digunakan sebagai bahan bakar kendaraan yang menggunakan mesin diesel. Pada umumnya solar akan banyak mengandung belerang karena dibandingkan dengan bensin solar memiliki titik didih yang lebih tinggi. Kualitas dari solar ditentukan dengan bilangan setana, yaitu tingkat kemudahan minyak solar untuk menyala atau terbakar di dalam mesin diesel.

\section{c. Minyak tanah}

Minyak tanah atau kerosene adalah cairan hidrokarbon yang tak berwarna dan mudah terbakar yang diperoleh dengan cara distilasi fraksional dari petroleum pada $150^{\circ} \mathrm{C}$ dan $275^{\circ} \mathrm{C}$ dan mempunyai rantai karbon dari $\mathrm{C}_{11}$ sampai $\mathrm{C}_{15}$. Biasanya, minyak tanah di distilasi langsung dari minyak mentah membutuhkan perawatan khusus, dalam sebuah unit Merox atau hidrotreater, untuk mengurangi kadar belerang dan pengaratannya. Minyak tanah dapat juga diproduksi oleh hidrocracker, yang digunakan untuk memperbaiki kualitas bagian dari minyak mentah yang akan bagus untuk bahan bakar minyak.

d. Premium

Premium adalah bahan bakar minyak jenis distilat berwarna kekuningan yang jernih. Premium merupakan BBM untuk kendaraan bermotor yang paling populer di Indonesia. Premium di Indonesia dipasarkan oleh Pertamina dengan harga yang relatif murah karena memperoleh subsidi dari Anggaran Pendapatan dan Belanja Negara. Premium merupakan BBM dengan oktan atau Research Octane Number (RON) terendah di antara BBM untuk kendaraan bermotor lainnya, yakni hanya 88. Pada umumnya, Premium digunakan untuk bahan bakar kendaraan bermotor bermesin bensin, seperti: mobil, sepeda motor, motor tempel, dan lain-lain. Bahan bakar ini sering juga disebut motor gasoline atau petrol.

\section{Kantong Plastik Jenis Kresek}

Kantong plastik jenis kresek dan kemasan plastik lainnya merupakan alat pengemas yang paling banyak dipergunakan karena murah, praktis dan mudah didapat. Plastik adalah istilah umum bagi polimer, yaitu material yang terdiri dari rantai panjang karbon dan elemen-elemen lain (oksigen, nitrogen, klorin atau belerang) yang mudah dibuat menjadi berbagai bentuk dan ukuran. Bahan pembuat plastik pada mulanya adalah minyak dan gas sebagai sumber alami, tetapi di dalam perkembangannya bahan-bahan ini digantikan dengan bahan sintesis sehingga dapat diperoleh sifat-sifat plastik yang diinginkan.

\section{Proses Pengolahan Sampah Plastik}

Proses pengolahan sampah plastik menjadi bahan bakar meliputi beberapa proses, diantaranya :

1. Pirolisis adalah dekomposisi kimia bahan organik melalui proses pemanasan tanpa atau sedikit oksigen atau reagen kimia lainya dimana material mentah akan mengalami pemecahan stuktur kimia menjadi fase gas. Teknik seperti ini mampu menghasilkan gas pembakaran yang berguna dan aman bagi lingkungan Proses pirolisis ini akan memecah hidrokarbon rantai karbon panjang dari polimer plastik menjadi rantai hidrokarbon berantai pendek, selanjutnya molekulmolekul ini didinginkan menjadi fase cair.

2. Distilasi adalah pemisahan campuran dalam suatu larutan berdasarkan perbedaan titik didih.

Rodiansono dkk., (2007) melakukan perengkahan sampah plastik jenis polipropilena dari kemasan air mineral dalam reaktor pirolisis terbuat dari stainless steel, dilakukan pada temperatur $475^{\circ} \mathrm{C}$ dengan dialiri gas nitrogen (100 $\mathrm{ml} / \mathrm{menit}$ ). Sebagai contoh, proses pirolisis plastik jenis polietilen ditunjukkan pada gambar 1 skema reaksi di bawah ini:

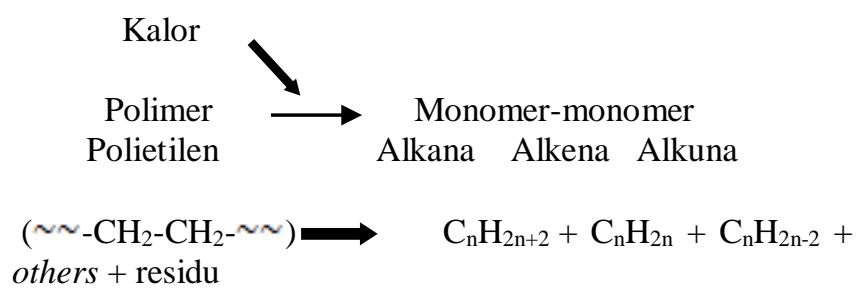

Gambar 1. Skema sederhana reaksi pirolisis plastik

\section{METODOLOGI}

Tahap pembuatan ialah proses produksi bahan bakar yaitu dari limbah kantong plastik jenis kresek dengan menggunakan metode pirolisis dan tahap analisis adalah tahap menganalisa nilai kalor, titik nyala (flash point), kadar abu, kadar air dan analisa komposisi yang terkandung dalam produk bahan bakar.

Berat sampel 500 gram dan ukuran $1-2 \mathrm{~cm}^{2}$. Suhu pirolisis: $260^{\circ} \mathrm{C}, 270^{\circ} \mathrm{C}, 280^{\circ} \mathrm{C}, 290^{\circ} \mathrm{C}$ dan $300^{\circ} \mathrm{C}$ dan waktu pirolisis :0, 15, 30, 45, 60 menit. Setelah bahan bakar yang diperoleh diambil untuk dianalisa nilar kalor, titik nyala (flash point), kadar abu, kadar air dan analisa komposisi. 
III.

\section{Nilai Kalor Bahan Bakar Minyak}

Pada penelitian ini nilai kalor bahan bakar minyak dari limbah kantong plastik jenis kresek dihitung berdasarkan komposisi kimia dari hasil analisa GC-MS. Berdasarkan dari hasil perhitungan komposisi kimia pada bahan bakar minyak, maka nilai kalor yang diperoleh untuk kantong plastik jenis kresek yaitu sebesar $10.541,75 \mathrm{kkal} / \mathrm{kg}$. Nilai kalor yang diperoleh pada plastik jenis kresek tidak jauh berbeda dan sesuai dengan standar mutu nilai kalor bahan bakar minyak pada umumnya yaitu antara 18.300-19.800 BTU/lb atau $10.160-11.000 \mathrm{kkal} / \mathrm{kg}$ (Syafari, 2011).

\section{Pengaruh Suhu dan Waktu Pirolisis Terhadap Titik Nyala}

Semakin tinggi suhu pirolisis, nilai titik nyala yang diperoleh semakin menurun, namun masih mendekati standar mutu bahan bakar minyak. Hal ini disebabkan oleh semakin tingginya suhu pirolisis, maka semakin cepat pula api menyambar ketika disulut karena dipengaruhi oleh kandungan air dalam minyak. Menurut Tjokrowisastro dkk (1990), semakin tinggi suhu pirolisis maka semakin sedikit kandungan air dalam minyak tersebut sehingga api cepat menyambar dan titik nyala yang diperoleh semakin kecil.

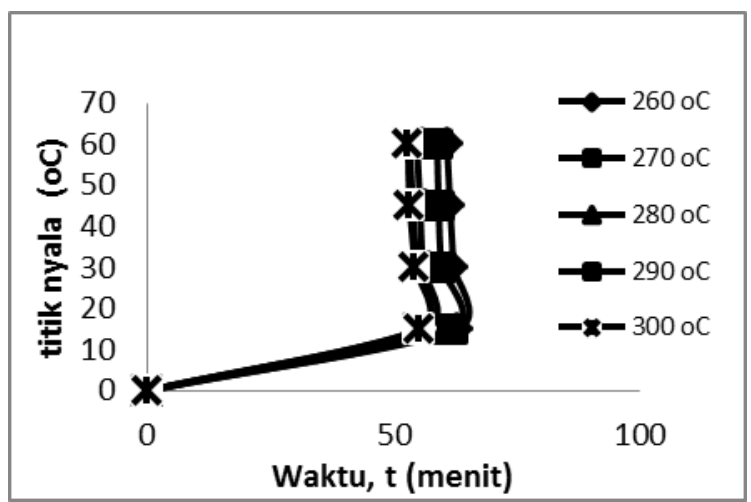

Gambar 2. Hubungan pengaruh suhu dan waktu pirolisis terhadap titik nyala (flash point) pada bahan bakar minyak limbah kantong plastik jenis kresek.
Pengaruh Suhu dan Waktu Pirolisis Terhadap Kadar Abu

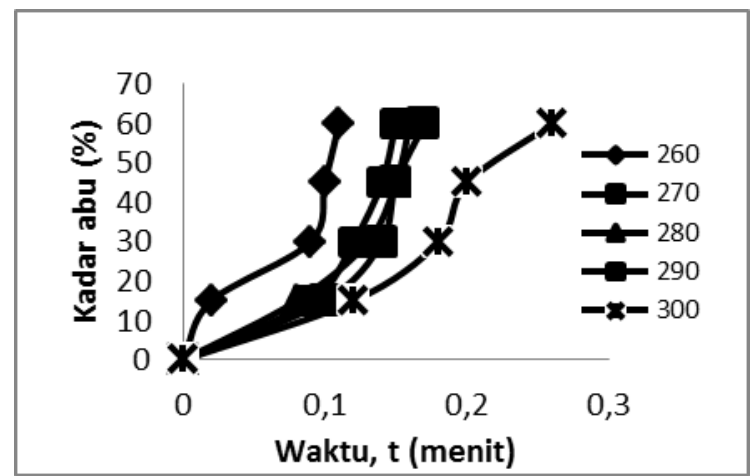

Gambar 3. Hubungan pengaruh suhu dan waktu pirolisis terhadap kadar abu pada bahan bakar minyak dari limbah kantong plastik jenis kresek

Dari gambar 3, bisa dilihat bahwa semakin tinggi suhu pirolisis maka kadar abu semakin naik, hal ini disebabkan oleh banyaknya hidrokarbon yang beratom $\mathrm{C}$ tinggi menjadi produk pirolisis. Semakin banyak atom C tinggi yang terkandung, maka kadar abu juga semakin tinggi. Karena kadar abu adalah atom $\mathrm{C}$ yang tidak terkonversi saat reaksi oksidasi berlangsung.

Hasil kadar abu yang didapat pada penelitian ini memang belum memenuhi standar mutu bahan bakar minyak, namun ada beberapa produk yang didapat sudah mendekati standar mutu bahan bakar minyak di Indonesia. Umumnya, standar mutu kadar abu bahan bakar minyak di Indonesia berada pada kisaran 0,03 - 0,7\% (Tjokrowisastrodkk, 1990).

\section{Pengaruh Suhu dan Waktu Pirolisis Terhadap Kadar} Air

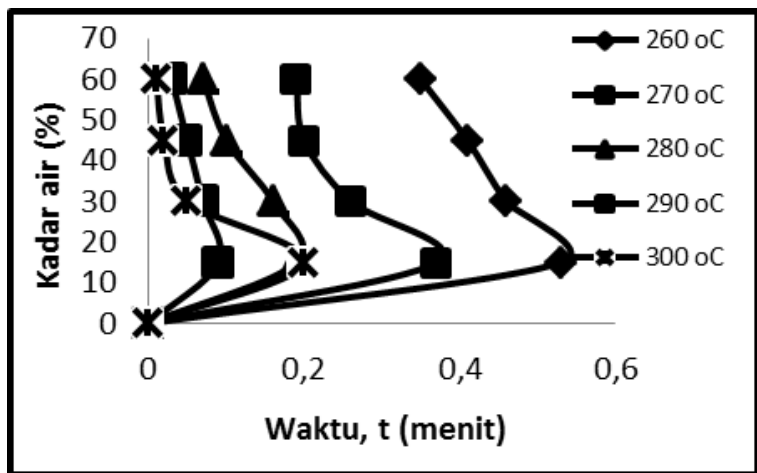

Gambar 4. Hubungan pengaruh suhu dan waktu pirolisis terhadap kadar air

Kadar air dalam bahan bakar minyak merupakan salah satu tolak ukur mutu bahan bakar minyak tersebut. Semakin kecil kadar air dalam bahan bakar minyak maka mutunya 
akan semakin baik, karena air adalah penyebab keharusan pada sistem pompa bakarnya. (Tjokrowisastro dkk, 1990).

\section{Pengujian Komposisi Kimia}
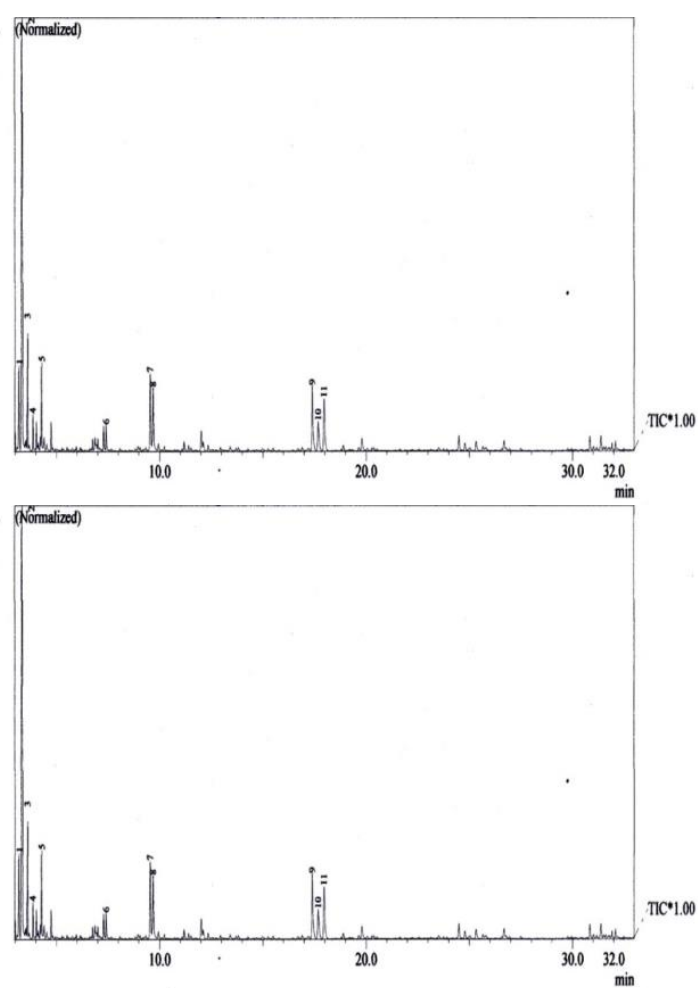

Gambar 5. Hasil analisa GC-MS dari bahan bakar minyak pirolisis kantong plastik jenis kresek.

Pengujian GC-MS mengidentifikasi beberapa komponen dari bahan bakar minyak tersebut, hasil analisa GC-MS menunjukkan 11 komposisi yang terdapat pada bahan bakar minyak dari limbah kantong plastik jenis kresek. Komposisi tersebut terdiri dari $\mathrm{C}_{12} \quad \mathrm{H}_{24}$ sebanyak 41,9\%, $\mathrm{C}_{7} \mathrm{H}_{8}$ sebanyak $23,1 \%, \mathrm{C}_{8} \mathrm{H}_{10}$ sebanyak $12,3 \%, \mathrm{C}_{15} \mathrm{H}_{30}$ sebanyak $8,4 \%, \mathrm{C}_{14} \mathrm{H}_{30}$ sebanyak $13,7 \%, \mathrm{C}_{11} \mathrm{H}_{22}$ sebanyak $19,9 \%$ dan $\mathrm{C}_{8} \mathrm{H}_{8}$ sebanyak $13,4 \%$.

\begin{tabular}{|c|c|l|c|c|}
\hline Peak & $\%$ mol & \multicolumn{1}{|c|}{ Nama } & $\begin{array}{c}\text { Formula } \\
\text { Kimia }\end{array}$ & MW \\
\hline 1 & 20.18 & Cylopropane & $\mathrm{C}_{12} \mathrm{H}_{24}$ & 168 \\
\hline 2 & 16.17 & Benzene, methyl-(CAS) & $\mathrm{C}_{7} \mathrm{H}_{5}$ & 92 \\
\hline 3 & 3.85 & Z-10-Pentadecen & $\mathrm{C}_{3} \mathrm{H}_{10}$ & 106 \\
\hline 4 & 5.92 & Undecane (CAS) n-undecane & $\mathrm{C}_{15} \mathrm{H}_{30}$ & 226 \\
\hline 5 & 9.20 & 1- deene, 2,4 di-methyl & $\mathrm{C}_{12} \mathrm{H}_{24}$ & 168 \\
\hline 6 & 9.60 & Ethanol, 2-(dodecyloxy) & $\mathrm{C}_{14} \mathrm{H}_{30}$ & 230 \\
\hline 7 & 6.89 & Benzene, ethyl-(CAS) & $\mathrm{C}_{3} \mathrm{H}_{10}$ & 106 \\
\hline 8 & 13.96 & 1- Undecane & $\mathrm{C}_{11} \mathrm{H}_{22}$ & 154 \\
\hline 9 & 4.78 & Benzene, 1,2- dimity-(CAS) & $\mathrm{C}_{8} \mathrm{H}_{10}$ & 106 \\
\hline 10 & 5.54 & Styrene \$\$, Benzene & $\mathrm{C}_{8} \mathrm{H}_{8}$ & 120 \\
\hline 11 & 3.90 & Ethanone, 1-phenyl & $\mathrm{C}_{8} \mathrm{H}_{8}$ & 120 \\
\hline
\end{tabular}

\section{Pengaruh Waktu dan Suhu Terhadap Massa Plastik}

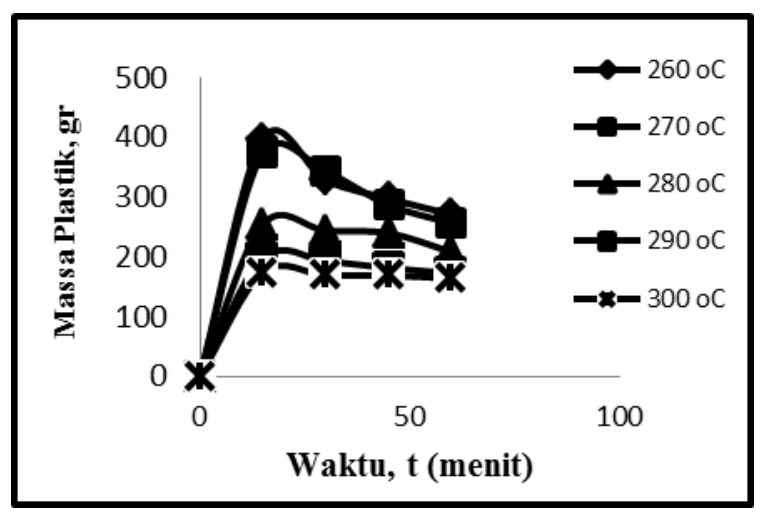

Gambar 6. Pengaruh waktu dan suhu terhadap massa plastik.

Gambar 6, menunjukkan bahwa pada suhu $260^{\circ} \mathrm{C}$ dengan waktu operasi 15-60 menit massa plastik sebesar 397,2271,1 gram. Pada suhu $300^{\circ} \mathrm{C}$ penurunan massa plastik menurun hingga 163,9 gram pada waktu operasi 60 menit. Hal ini menunjukkan semakin tinggi suhu pirolisis, maka massa plastik yang ada di dalam reaktor akan semakin turun.

Dengan bertambah tingginya suhu pemanasan maka zat-zat yang terkandung dalam plastik akan terurai dengan sempurna. Zat-zat tersebut akan terurai menjadi gas dan cair (minyak). (Tjokrowisastro dkk, 1990).

\section{Penentuan Energi Aktivasi}

Energi aktivasi adalah energi minimum agar molekulmolekul dapat bereaksi. Semakin rendah temperatur, nilai eksponen negatif semakin besar, sehingga nilai $\mathrm{k}$ semakin kecil, sehingga laju semakin lambat, sedangkan semakin tinggi temperatur, nilai eksponen negatif semakin kecil, nilai k yang didapat semakin besar, yang berarti bahwa laju yang terjadi semakin cepat.

Harga $\mathrm{k}$ yang diperoleh dalam penelitian ini adalah 0,0307 (menit) $^{-1}$ dan nilai energi aktivasi yang didapat adalah $10.106,77 \mathrm{kj}$

\section{KESIMPULAN}

1. Nilai kalor yang diperoleh dari hasil perhitungan komposisi kimianya sebesar $10.541,75 \mathrm{kkal} / \mathrm{kg}$

2. Titik nyala dari beberapa sampel produk yang didapat memenuhi standar mutu bahan bakar minyak di Indonesia, diantaranya yang paling mendekati titik minimum pada suhu pirolisis $300^{\circ} \mathrm{C}$ yaitu $57,5^{\circ} \mathrm{C}$. 
3. Semakin tinggi suhu pirolisis maka semakin sedikit persen kadar air yang diperoleh yaitu berkisar antara $0,01-0,53 \%$.

4. Semakin tinggi suhu pirolisis maka semakin banyak pula persen kadar abu yang dihasilkan tertinggi pada suhu $300^{\circ} \mathrm{C}$ yaitu $0.26 \%$, terendah pada suhu $260^{\circ} \mathrm{C}$ yaitu $0,01 \%$.

5. Komposisi limbah kantong plastik jenis kresek dapat mempengaruhi pembentukan distribusi jumlah atom $\mathrm{C}$ senyawa hidrokarbon minyak pirolisis. Hasil dari analisa komposisi GC-MS diperoleh komposisi yang paling dominan adalah $\mathrm{C}_{12} \mathrm{H}_{24}$ yaitu sebesar $41,9 \%$.

6. Nilai energi aktivasi yang didapat adalah 10.106,77 $\mathrm{kj} / \mathrm{mol}$.

\section{REFERENSI}

[1] AR Hakim, 2012, Pemanfaatan Limbah Padat (plastik) Sebagai Bahan Baku Pembuatan Bahan Bakar Pengganti Bensin. Jurnal Jurusan Teknik Lingkungan FTSP UPN "Veteran” Jatim, 2012.

[2] BPS dan Bappeda Kota Lhokseumawe, Lhokseumawe Dalam Angka 2014, Kerjasama Badan Pusat Statistik dan Badan Perencanaan Pembangunan Daerah Kota Lhokseumawe, 2014.

[3] Puspita, Informasi Energi Indonesia, Jurusan Teknik Lingkungan FTSP UPN Veteran, Jatim, 2013.

[4] Fogler, H.S., Element of Chemical Reaction Reaction Engineering, Edisi ke-3, Prentice-Hall, New Jersey, 1999.

[5] Rodiansono,Trisunaryanti,W., dan Triyono, Pembuatan dan Uji Aktivitas Katalis NiMo/Z pada Reaksi Hidrorengkah Fraksi Sampah Plastik menjadi Fraksi Bensin, Berkala MIPA, 17, 2, 2007.

[6] Syafitri, C, Analisis Aspek Sosial Ekonomi Pemanfaatan Limbah Plastik, Program Pascasarjana Institut Pertanian Bogor, 2001.

[7] Tjokrowisastro, E. H., dkk, Teknik Pembakaran Dasar Dan Bahan Bakar, Diktat ITS-Surabaya, 1990. 